\title{
Novel use of flow diversion for the treatment of aneurysms associated with arteriovenous malformations
}

\author{
Craig Kilburg, MD, Philipp Taussky, MD, M. Yashar S. Kalani, MD, PhD, and Min S. Park, MD \\ Department of Neurosurgery, Clinical Neurosciences Center, University of Utah, Salt Lake City, Utah
}

\begin{abstract}
The use of flow-diverting stents for intracranial aneurysms has become more prevalent, and flow diverters are now routinely used beyond their initial scope of approval at the proximal internal carotid artery. Although flow diversion for the treatment of cerebral aneurysms is becoming more commonplace, there have been no reports of its use to treat flow-related cerebral aneurysms associated with arteriovenous malformations (AVMs). The authors report the cases of 2 patients whose AVM-associated aneurysms were managed with flow diversion. A 40-year-old woman presented with a history of headaches that led to the identification of an unruptured Spetzler-Martin Grade V, right parietooccipital AVM associated with 3 aneurysms of the ipsilateral internal carotid artery. Initial attempts at balloon-assisted coil embolization of the aneurysms were unsuccessful. The patient underwent placement of a flow-diverting stent across the diseased vessel; a 6-month follow-up angiogram demonstrated complete occlusion of the aneurysms. In the second case, a 57-year-old man presented with new-onset seizures, and an unruptured Spetzler-Martin Grade V, right frontal AVM associated with an irregular, wide-necked anterior communicating artery aneurysm was identified. The patient underwent placement of a flow-diverting stent, and complete occlusion of the aneurysm was observed on a 7-month follow-up angiogram. These 2 cases illustrate the potential for use of flow diversion as a treatment strategy for feeding artery aneurysms associated with AVMs. Because of the need for dual antiplatelet medications after flow diversion in this patient population, however, this strategy should be used judiciously.
\end{abstract}

https://thejns.org/doi/abs/10.3171/2017.2.FOCUS1755

KEY WORDS arteriovenous malformation; cerebral aneurysm; flow diversion; flow-diverting stent

$\mathrm{C}$ EREBRAL aneurysms are identified in $7.5 \%-23.5 \%$ of patients with arteriovenous malformations (AVMs). ${ }^{4,6-8,10,11,13,15,16,20,23}$ They can be found on a feeding artery or within the AVM proper and represent an elevated risk for intracranial hemorrhage when compared with AVMs without associated aneurysms. ${ }^{4,7}$ These lesions likely form as a result of a combination of congenital factors, as well as the increased flow demands of the AVM. $.6,8,13,16,20,22,23$

Treatment of cerebral aneurysms in these cases is complicated by the presence of the AVM. If indicated, the aneurysm can be treated separately from the AVM or surgically at the time of the AVM treatment. Coil embolization has been the mainstay of endovascular treatment when aneurysm treatment is performed separately from any planned AVM treatment. . $^{2,13,21}$

Flow diversion technology has introduced a new technique for the treatment of large and giant cerebral aneurysms of the internal carotid artery (ICA). ${ }^{3,17}$ Since its introduction, there has been growing enthusiasm for its use in cerebral aneurysms that do not fall within the initial indications. ${ }^{1,5,9,12,14,19}$ Its use, however, must be tempered by the concomitant need for prolonged dual antiplatelet medications, because catastrophic hemorrhages associated with the use of these medications after flow diversion are well described in the literature..$^{5,18}$ It is likely because of these concerns that flow diversion in these instances has not been previously reported. We present 2 cases in which 

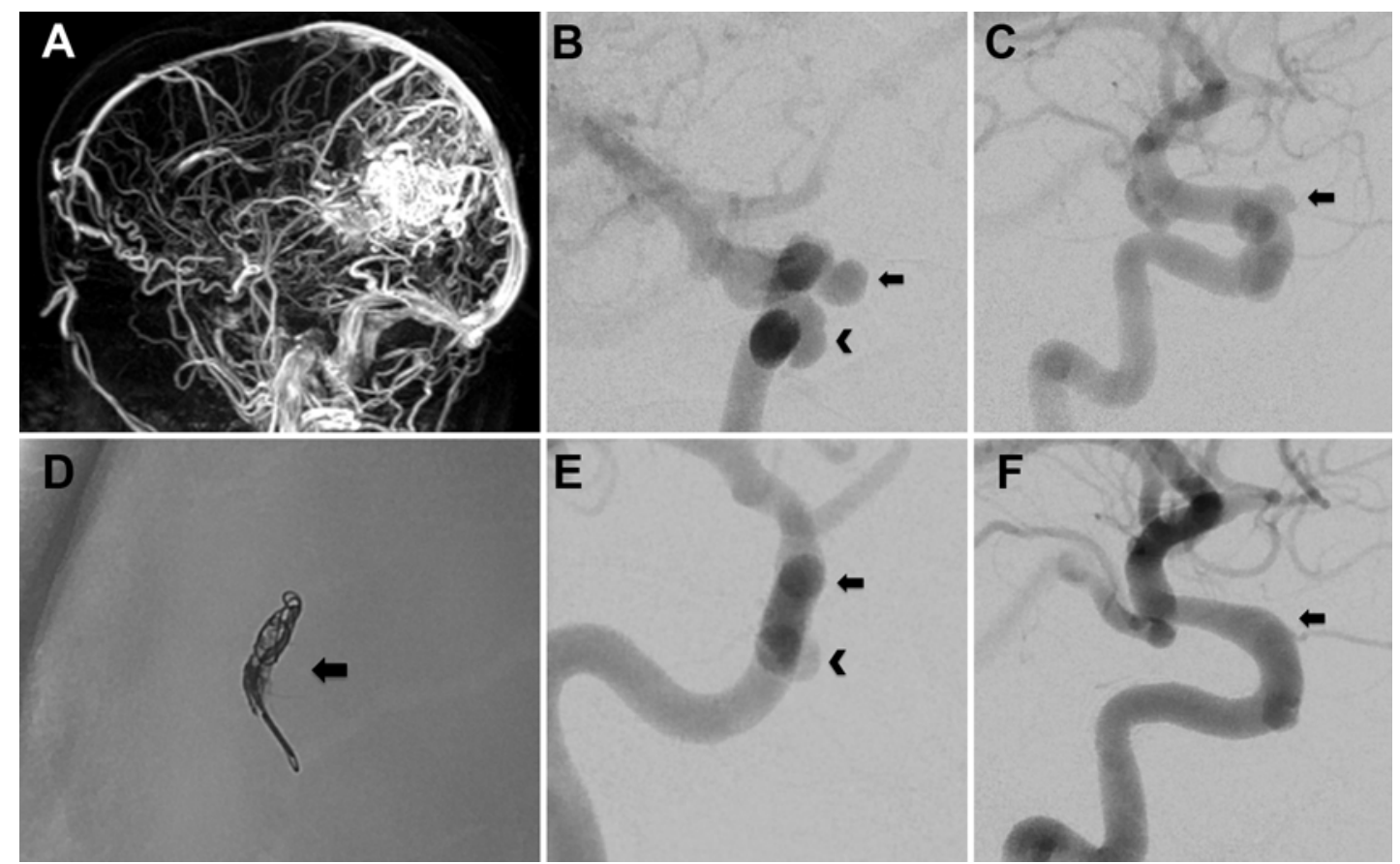

FIG. 1. A: Magnetic resonance angiogram reconstruction of a Spetzler-Martin Grade V parietooccipital AVM. B: Right ICA angiogram demonstrating cavernous ICA (arrowhead) and superior hypophyseal (arrow) artery aneurysms. C: Right ICA angiogram demonstrating a small ophthalmic artery aneurysm (arrow). D: Lateral unsubtracted view demonstrating the migrated coil mass (arrow). E: Six-month follow-up angiogram demonstrating complete occlusion of the superior hypophyseal artery aneurysm (arrow) and incomplete occlusion of the cavernous ICA aneurysm (arrowhead). F: Six-month follow-up angiogram demonstrating complete occlusion of the ophthalmic artery aneurysm (arrow).

cerebral aneurysms associated with AVMs were successfully treated with flow diversion, with occlusion of the aneurysms at short-term follow-up. This case report was granted a waiver of informed consent by the University of Utah Investigational Review Board.

\section{Case Reports}

\section{Case 1}

\section{Presentation and Examination}

A 40-year-old woman presented with a history of migraine headaches; noninvasive imaging studies revealed a Spetzler-Martin Grade V AVM. A diagnostic cerebral angiogram demonstrated a 6-cm right parietooccipital AVM with deep and superficial venous drainage (Fig. 1A). In addition, there were 3 aneurysms of the ipsilateral ICA: one aneurysm at the anterior genu/cavernous segment, another at the superior hypophyseal segment, and a smaller aneurysm of the ophthalmic segment (Fig. 1B and C).

At the time of the patient's initial evaluation, we recommended against treatment of the AVM but did recommend treatment of the right ICA aneurysms. She declined surgical treatment but agreed to treatment of the superior hypophyseal aneurysm with balloon-assisted coil embolization.

\section{Treatment}

During the initial attempts at balloon-assisted coil embolization, the procedure was complicated by downstream migration of the initial framing coil after a loss of microcatheter access necessitated balloon deflation. Fortunately, the coil migrated into a distal middle cerebral artery feeding artery just proximal to the AVM. We then proceeded with Onyx (Medtronic) embolization of the feeding artery and a small portion of the AVM (Fig. 1D).

After further discussions with the patient on treatment options for her cerebral aneurysms, she elected to proceed with flow diversion despite the inherent risks of dual antiplatelet medications in her situation. The patient was premedicated with $325 \mathrm{mg}$ of aspirin and $75 \mathrm{mg}$ of clopidogrel daily for 5 days prior to her planned treatment, and P2Y12 testing demonstrated an adequate response before the procedure was initiated. She underwent uncomplicated placement of a single $5 \times 25-\mathrm{mm}$ Pipeline Flex device (Medtronic) and was discharged home the following day.

\section{Follow-Up}

The patient continued to do well clinically after her treatment. A follow-up diagnostic cerebral angiogram 6 months after her treatment demonstrated occlusion of her ophthalmic and superior hypophyseal aneurysms and partial occlusion of the cavernous aneurysm (Fig. 1E and F).

\section{Case 2}

Presentation and Examination

A 57-year-old man presented after a new-onset seizure; noninvasive imaging studies demonstrated a SpetzlerMartin Grade V AVM. A diagnostic cerebral angiogram 

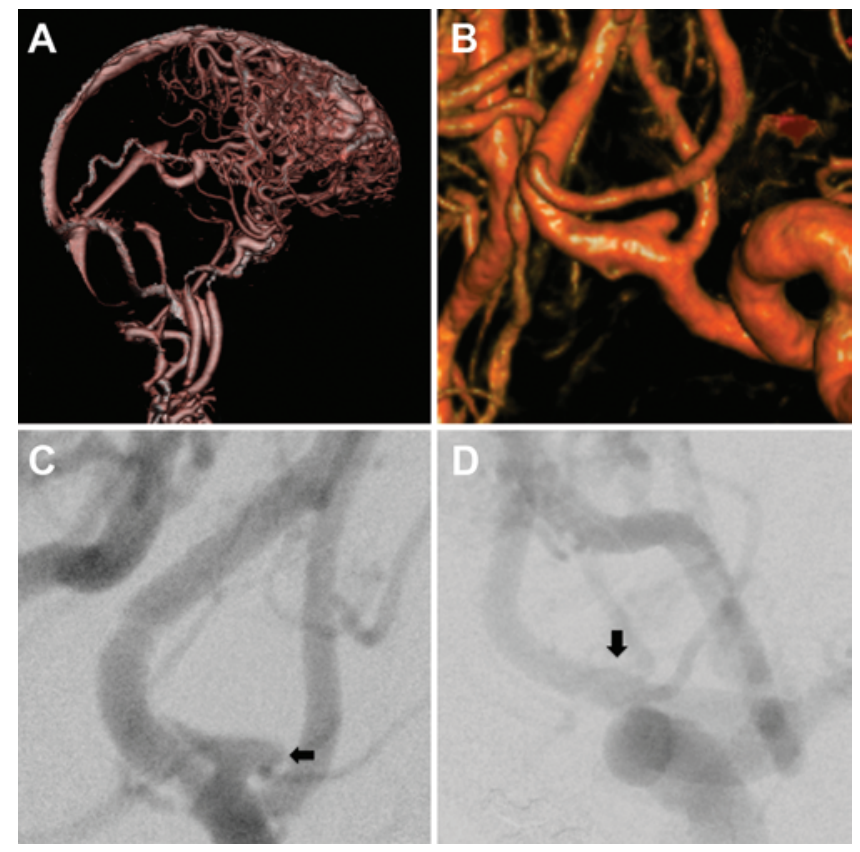

FIG. 2. A: 3D CT angiogram reconstruction of the Spetzler-Martin Grade V frontal AVM. B: 3D rotational angiogram demonstrating a small, irregular anterior communicating artery aneurysm. C: Left ICA angiogram showing the aneurysm (arrow) after flow diversion. D: Seven-month follow-up angiogram demonstrating complete occlusion of the anterior communicating artery aneurysm (arrow).

demonstrated an 11-cm right frontal AVM with deep and superficial venous drainage (Fig. 2A). In addition, there was a wide-necked, irregular, 3-mm aneurysm of the anterior communicating artery (Fig. 2B).

At the time of the initial evaluation, we recommended against treatment of the AVM but did recommend treatment of the anterior communicating artery aneurysm. Because of the presence of the AVM, the patient declined surgical treatment of the aneurysm. Moreover, it was believed that the wide neck of the aneurysm would preclude endovascular treatment without the use of a stent. Therefore, we recommended treatment by deployment of a flowdiverting stent.

\section{Treatment}

The patient was premedicated with $325 \mathrm{mg}$ of aspirin and $75 \mathrm{mg}$ of clopidogrel daily for 5 days prior to the planned treatment. P2Y12 testing demonstrated an adequate response, and he underwent placement of 2 Pipeline Flex devices (Fig. 2C). The procedure was complicated by the formation of a small, nonocclusive thrombus within the device, which resolved with intraarterial administration of abciximab. The patient did well after the procedure, without any sequelae of the transient intraprocedural thrombus, and was discharged home the next day.

\section{Follow-Up}

A diagnostic cerebral angiogram at 7-month follow-up demonstrated occlusion of the anterior communicating artery aneurysm (Fig. 2D).

\section{Discussion}

Aneurysms are frequently associated with AVMs.,6$8,10,11,13,15,16,20,23$ They are typically located within the AVM nidus or on proximal feeding vessels. AVMs with associated aneurysms have an increased rupture rate of $7 \%-10 \%$ when compared with the $2 \%-4 \%$ rupture rate of AVMs without related aneurysms., ${ }^{4,8,2,20}$ Although definitive treatment of the AVM should be the ultimate goal and has been shown to lead to the regression of aneurysms on proximal feeding vessels, ${ }^{11,20}$ this may not be feasible in some instances because of patient demographics or AVM size, venous drainage pattern, or anatomical location. In these circumstances, focused treatment of the associated aneurysm alone may be reasonable to help reduce the risk of intracranial hemorrhage back to the baseline level of AVMs without associated intracranial aneurysms. $2,4,7,8,13,20,21,23$

When considering whether to treat flow-related aneurysms, the practitioner must weigh the risks of aneurysm rupture versus the risks of the selected treatment method. The rate of complications associated with the treatment of aneurysms by flow diversion is not benign. ${ }^{5,9,18}$ Additionally, whether treatment of flow-related aneurysms associated with AVMs improves the natural history of AVM rupture is not well known. As a result, it is important to have an in-depth discussion with the patient to explain the characteristics of the AVM and the flow-related aneurysm and how those factors potentially influence the decision to proceed with observation versus treatment. Since the rupture risk of AVM-associated aneurysms is not well known, observation may be considered as an option; however, because AVMs with associated aneurysms have a higher reported rate of intracranial hemorrhage, practitioners may attribute that difference to the presence of an aneurysm and propose treatment of the aneurysm. In both of our cases, we had multiple, extensive discussions with the patients regarding the risks of proceeding with aneurysm treatment as well as the risk of potentially exacerbating any intracranial hemorrhage from their AVM because of the requirements for dual antiplatelet therapy following placement of a flow diverter.

Treatment of AVM-related aneurysms has primarily been achieved via coil embolization, although other strategies, such as Onyx or $N$-butyl cyanoacrylate (NBCA) embolization and ethanol sclerotherapy, have also been used. ${ }^{2,13,21}$ Coil embolization is used principally for obliteration of the aneurysm itself, whereas Onyx or NBCA embolization is often used for occlusion of the artery from which the aneurysm arises. Infrequently, Onyx and NBCA have been used for focused obliteration of the aneurysm with preservation of flow within the parent artery. ${ }^{2}$

To our knowledge, the use of flow diversion for the treatment of proximal feeding vessel aneurysms has not been evaluated. We detail 2 successful cases in which this strategy was used, including in a partial salvage circumstance when attempted balloon-assisted coil embolization failed. These 2 cases also indicate that this technique may be useful in a variety of vessel calibers. Because of size constraints of the devices and treated vessels, however, it will most likely remain a feasible technique only for aneurysms located on proximal vessels and not intranidal aneurysms. 
Within the limitations of our small sample size and experience from a single center, our success in these 2 highly selected cases suggests that the technique can be used safely when more traditional treatment options are unsuccessful or not an option. Despite this, we still believe that it should be used very cautiously. Although the risk of rupture from the treated aneurysm lasts until the aneurysm occludes and endothelialization occurs across the device, the risk of rupture from the AVM remains throughout the patient's life. In the setting of single or dual antiplatelet medications, the potential for significant consequences remains.

There is also the concern that flow diversion may not be as successful at occluding aneurysms in the high-flow state of AVMs as it is in traditional aneurysm cases. Flow diversion works by limiting the flow of blood into the lumen of the aneurysm by directing the majority of the blood flow distally through the parent artery. This allows for stasis of blood within the aneurysm with resultant thrombosis, the eventual endothelialization across the flow diverter, and ultimately the exclusion of the aneurysm. Theoretically, in the high-flow state within a proximal feeding vessel to an AVM, the flow through the vessel and device could be too significant to allow for stasis to occur. However, as is shown in our cases, in carefully selected patients, flow diversion has the potential to lead to aneurysm occlusion even in a high-flow state.

Placing a flow diverter in the high-flow setting of an AVM also raises the theoretical concern that the device could direct more of this high flow into the nidus of the $\mathrm{AVM}$, increasing the risk of AVM rupture. However, flow diverters do not change the overall amount of flow within a vessel; they only direct a portion of the arterial flow away from the aneurysm lumen. Therefore, it appears unlikely that the flow to the AVM nidus would change much over baseline.

\section{Conclusions}

We describe 2 cases of successful flow diversion of feeding artery cerebral aneurysms associated with AVMs in which short-interval angiography demonstrated complete occlusion of the aneurysms. Enthusiasm for this strategy should be tempered with the risks of dual antiplatelet medications in this potentially high-risk patient cohort, and its use should be restricted to carefully selected patients. We would only recommend flow diversion as a treatment for AVM-associated aneurysms when other treatment options have failed or are not viable options. Additionally, there must be a thorough discussion with the patient regarding the potential risk of exacerbating intracranial hemorrhages on antiplatelet medications. Further study is necessary before flow diversion for treatment of AVM-related aneurysms could be recommended either routinely or as a salvage procedure.

\section{Acknowledgments}

We thank Kristin Kraus, MSc, for her invaluable assistance with the preparation of this manuscript.

\section{References}

1. Albuquerque FC, Park MS, Abla AA, Crowley RW, Ducruet AF, McDougall CG: A reappraisal of the Pipeline embolization device for the treatment of posterior circulation aneurysms. J Neurointerv Surg 7:641-645, 2015

2. Alexander MD, Cooke DL, Hallam DK, Kim H, Hetts SW, Ghodke BV: Less can be more: targeted embolization of aneurysms associated with arteriovenous malformations unsuitable for surgical resection. Interv Neuroradiol 22:445451, 2016

3. Becske T, Kallmes DF, Saatci I, McDougall CG, Szikora I, Lanzino G, et al: Pipeline for uncoilable or failed aneurysms: results from a multicenter clinical trial. Radiology 267:858868,2013

4. Brown RD Jr, Wiebers DO, Forbes GS: Unruptured intracranial aneurysms and arteriovenous malformations: frequency of intracranial hemorrhage and relationship of lesions. J Neurosurg 73:859-863, 1990

5. Chitale R, Gonzalez LF, Randazzo C, Dumont AS, Tjoumakaris $\mathrm{S}$, Rosenwasser R, et al: Single center experience with pipeline stent: feasibility, technique, and complications. Neurosurgery 71:679-691, 2012

6. Cunha e Sa MJ, Stein BM, Solomon RA, McCormick PC: The treatment of associated intracranial aneurysms and arteriovenous malformations. J Neurosurg 77:853-859, 1992

7. da Costa L, Wallace MC, ter Brugge KG, O'Kelly C, Willinsky RA, Tymianski M: The natural history and predictive features of hemorrhage from brain arteriovenous malformations. Stroke 40:100-105, 2009

8. Flores BC, Klinger DR, Rickert KL, Barnett SL, Welch BG, White JA, et al: Management of intracranial aneurysms associated with arteriovenous malformations. Neurosurg Focus 37(3):E11, 2014

9. Griessenauer CJ, Ogilvy CS, Foreman PM, Chua MH, Harrigan $\mathrm{MR}$, He L, et al: Pipeline embolization device for small intracranial aneurysms: evaluation of safety and efficacy in a multicenter cohort. Neurosurgery 80:579-587, 2017

10. Gross BA, Du R: Natural history of cerebral arteriovenous malformations: a meta-analysis. J Neurosurg 118:437-443, 2013

11. Kano H, Lunsford LD, Flickinger JC, Yang HC, Flannery TJ, Awan NR, et al: Stereotactic radiosurgery for arteriovenous malformations, Part 1: management of Spetzler-Martin Grade I and II arteriovenous malformations. J Neurosurg 116:11-20, 2012

12. Levitt MR, Park MS, Albuquerque FC, Moon K, Kalani MY, McDougall CG: Posterior inferior cerebellar artery patency after flow-diverting stent treatment. AJNR Am J Neuroradiol 37:487-489, 2016

13. Lv X, Wu Z, Li Y, Yang X, Jiang C, Sun Y, et al: Endovascular treatment of cerebral aneurysms associated with arteriovenous malformations. Eur J Radiol 81:1296-1298, 2012

14. Mazur MD, Kilburg C, Wang V, Taussky P: Pipeline embolization device for the treatment of vertebral artery aneurysms: the fate of covered branch vessels. J Neurointerv Surg 8:1041-1047, 2016

15. Mohr JP, Parides MK, Stapf C, Moquete E, Moy CS, Overbey JR, et al: Medical management with or without interventional therapy for unruptured brain arteriovenous malformations (ARUBA): a multicentre, non-blinded, randomised trial. Lancet 383:614-621, 2014

16. Morgan MK, Alsahli K, Wiedmann M, Assaad NN, Heller GZ: Factors associated with proximal intracranial aneurysms to brain arteriovenous malformations: a prospective cohort study. Neurosurgery 78:787-792, 2016

17. Nelson PK, Lylyk P, Szikora I, Wetzel SG, Wanke I, Fiorella D: The Pipeline embolization device for the intracranial treatment of aneurysms trial. AJNR Am J Neuroradiol 32:34-40, 2011 
18. Park MS, Albuquerque FC, Nanaszko M, Sanborn MR, Moon K, Abla AA, et al: Critical assessment of complications associated with use of the Pipeline embolization device. J Neurointerv Surg 7:652-659, 2015

19. Pistocchi S, Blanc R, Bartolini B, Piotin M: Flow diverters at and beyond the level of the circle of Willis for the treatment of intracranial aneurysms. Stroke 43:1032-1038, 2012

20. Redekop G, TerBrugge K, Montanera W, Willinsky R: Arterial aneurysms associated with cerebral arteriovenous malformations: classification, incidence, and risk of hemorrhage. J Neurosurg 89:539-546, 1998

21. Settecase F, Hetts SW, Nicholson AD, Amans MR, Cooke DL, Dowd CF, et al: Superselective intra-arterial ethanol sclerotherapy of feeding artery and nidal aneurysms in ruptured cerebral arteriovenous malformations. AJNR Am J Neuroradiol 37:692-697, 2016

22. Shakur SF, Amin-Hanjani S, Mostafa H, Charbel FT, Alaraj A: Hemodynamic characteristics of cerebral arteriovenous malformation feeder vessels with and without aneurysms. Stroke 46:1997-1999, 2015

23. Thompson RC, Steinberg GK, Levy RP, Marks MP: The management of patients with arteriovenous malformations and associated intracranial aneurysms. Neurosurgery 43:202-212, 1998

\section{Disclosures}

Dr. Taussky reports that he is a consultant for Medtronic.

\section{Author Contributions}

Conception and design: Park, Taussky. Acquisition of data: Park, Kilburg. Analysis and interpretation of data. Drafting the article: Park, Kilburg. Critically revising the article: Park, Taussky, Kalani. Reviewed submitted version of manuscript: all authors. Approved the final version of the manuscript on behalf of all authors: Park.

\section{Correspondence}

Min S. Park, Department of Neurosurgery, University of Utah, 175 N Medical Dr. East, Salt Lake City, UT 84132. email: neuropub@ hsc.utah.edu. 